\title{
Influences of carbon nanofillers on mechanical performance of epoxy resin polymer
}

\author{
Shraddha Singh $\cdot$ V. K. Srivastava • \\ Rajiv Prakash
}

Received: 21 April 2014/Accepted: 5 May 2014/Published online: 5 June 2014

(C) The Author(s) 2014. This article is published with open access at Springerlink.com

\begin{abstract}
The influence of multi-walled carbon nanotubes (MWCNTs) and graphene nanoplatelets (GnPs) on epoxy resin was investigated to compare their mechanical properties. MWCNT/epoxy resin and GnP/epoxy resin composites were compared with each other for their tensile strength, compressive strength, Charpy Impact and Izod impact energy with the variation of weight percentage ratio of nanofiller ranging from $0.5,1.0,2.0$ and 3.0, respectively. The result shows that $\mathrm{GnP} / \mathrm{epoxy}$ resin composite gave better tensile and compressive strength compared to MWCNT/epoxy resin composite whereas Izod impact energy, Charpy impact energy and dynamic fracture toughness of MWCNT/epoxy resin composite resulted in better impact resistance than the GnP/epoxy resin composite. Thermal stability and microstructural properties of composites were measured using Thermogravimetric analysis (TGA), transmission electron microscope (TEM) and scanning electron microscope (SEM).
\end{abstract}

Keywords Carbon - Composites - Mechanical properties - Thermogravimetric analysis .

Scanning electron microscopy

\section{Introduction}

Carbon-reinforced epoxy resin composites are often used in aircraft. Because of their high specific mechanical

S. Singh $\cdot$ R. Prakash

School of Materials Science and Technology, Indian Institute of Technology, (BHU), Varanasi 221005, India

V. K. Srivastava $(\bowtie)$

Department of Mechanical Engineering, Indian Institute

of Technology, (BHU), Varanasi 221005, India

e-mail: vijayks210@gmail.com properties, they are mainly used as structural components. Epoxy resin is sometimes used as a matrix material in these composites. Graphene nanoplatelets $(\mathrm{GnPs})$ and multiwalled carbon nanotubes (MWCNTs) are new carbon materials that have recently been developed. Graphene has generated much more interest due to its high specific area and novel mechanical, electrical and thermal properties. (Higginbotham et al. 2010; Stankovich et al. 2006; Jiao et al. 2009; Kosynkin et al. 2009; Li et al. 2008; Wang et al. 2009; Rafiee et al. 2010; Han et al. 2007) combined high electrical conductivity with record of thermal conductivity and mechanical properties. Used as additives, they can impart their properties to the materials and coatings they are added to. They have countless potential applications, some of which we cannot even begin to imagine today (Chen et al. 2007; Iijima 1991; Sinnott and Andrews 2001).

Carbon nanotubes are the most promising 1D material for nanotechnology, optical, electronic and composite material applications. Advances in carbon nanotube growth technique led to considerable increases in both production rates. Nanotube synthesis by CVD process was chosen because it offers a promising method to bulk production of high-purity nanotube that can be carried to commercialization. Useful composite research requires a bulk supply of nanotube of high purity and in a useable (i.e. easily dispersible) form. Existing technologies for the production of single-walled carbon nanotube (SWCNT) do not yield sufficient quantities and lack the required purity. Purification of these materials is often tedious, low in yield, and damaging to the tubes' structure through oxidative shortening. For applications such as conductive filler or as reinforcing fibre, MWCNT is likely to be preferred over SWCNT on a cost basis. Also, technologies developed for MWCNT applications can be directly transferred to SWCNT composites should SWCNT synthesis reach industrial scale (Gojny et al. 2005). 
One of the most promising applications of MWCNT and GnP materials is in polymer composite, which incorporates nano-scale filler materials. Polymer composites show substantial property enhancements at much lower loadings than polymer composites with conventional microscale fillers (such as glass or carbon fibre), which ultimately results in lower component weight and can simplify processing; moreover, the multifunctional property enhancements made possible with composites may create new applications of polymers (Dassios et al. 2012; King et al. 2013; Singh et al. 2013).

The main objective of the present work was to compare the mechanical properties of GnP/epoxy resin and MWCNT/epoxy resin composites with the variation of weight percentage ratio of nanofillers ranging from 0.5 , $1.0,2.0$ and 3.0 .

\section{Experimentation}

Materials and specimen preparation

Graphene nanoplatelet and multi-walled carbon nanotube were used as filler materials. Graphene nanoplatelet was obtained from J. K. Impex Company, Mumbai with $99.5 \%$ purities. Multi-walled carbon nanotube was available from TUHH, Harburg, Hamburg, Germany. Epoxy resin was obtained from Ciba-Geigy Ltd., Mumbai. The material properties are listed in Table 1.

First, araldite (LY-556) $55 \%$, hardener (HY-917) $49 \%$ and accelerator (DY-070) $0.28 \%$ were used as epoxy resin matrix. MWCNT filler was used as reinforcement in epoxy resin with weight percentage variation of MWCNT filler ranging from 0.5, 1.0, 2.0 and 3.0. MWCNT particle was manually mixed with the resin (LY-556). MWCNT filled resin was dispersed using a lab-scale three-roll-mill (Exakt 120 EXAKT Advanced Technology GmbH, Germany), which enables the introduction of very high shear forces (up to 200,000/s) throughout the suspension. The curing

Table 1 Material properties

\begin{tabular}{|c|c|c|}
\hline Material & Geometry & $\begin{array}{l}\text { Elastic modulus, } \\
\mathrm{GPa}\end{array}$ \\
\hline $\begin{array}{l}\text { MWCNT } \\
99.98 \%\end{array}$ & $\begin{array}{l}\text { Length }= \pm 2 \mu \mathrm{m} \\
\text { Average inner } \\
\text { diameter }= \pm 6.5 \mathrm{~nm} \\
\text { Average outer } \\
\text { diameter }= \pm 40 \mathrm{~nm}\end{array}$ & $1,000.0$ \\
\hline Epoxy resin & - & 2.0 \\
\hline $\begin{array}{l}\text { Graphene } \\
\text { nanoplatelet } \\
99.5 \%\end{array}$ & $\begin{array}{l}\text { Thickness }=8-10 \mathrm{~nm}, \\
\text { Diameter }=5.25 \mu \mathrm{m},\end{array}$ & $\begin{array}{l}\text { Elastic } \\
\quad \text { modulus }=1,006.0\end{array}$ \\
\hline
\end{tabular}

time $20 \mathrm{~min}$ is allowed to cure the specimen. The predispersed suspension was then given batchwise onto the roll with dwell times of $2 \mathrm{~min}$. The dispersive forces on the suspension were acting in the gap $(5 \mu \mathrm{m})$ between the rolls. After dispersion of the MWCNT in the resin LY-556, the hardener and accelerator were usually added in a vacuum dissolver, to avoid trapped air in the suspension. Then the mixture was placed in a vacuum chamber for $20 \mathrm{~min}$ to eliminate the bubbles introduced during the rolling process. The dispersed mixtures of MWCNT and resin were subsequently diluted by adding an appropriate amount of hardener (HY-917) in the weight ratio of 10:1. Again, MWCNT/epoxy resin mixture was dispersed by the same method and air bubble removed completely from the mixture before curing.

In this paper, we were considered to differentiate between mechanical properties of MWCNT/epoxy resin composite and GnP/epoxy resin composite with the same percentage of fillers. For this objective, GnP composite was manually mixed with the resin and then mixer was placed in the mechanical stirrer at the speed of $1 \mathrm{~m} / \mathrm{min}$ for $1 \mathrm{~h}$. After proper dispersion of graphene nanoplatelet in the resin, hardener was added to the weight ratio of 10:1. Again, mixture of graphene nanoplatelet (weight percentage variation of ranging from $0.5,1.0,2.0$ and 3.0) added to the resin and hardener was gently mixed with the stirrer and allowed removing the air bubble from the mixture. Finally, GnP/epoxy resin mixture was placed in vacuum for 20 min to escape out the bubbles introduced during the mixing process. The dispersed mixtures were poured into the mould and allowed curing the mixture for $24 \mathrm{~h}$. After curing, tensile, compressive, Izod and Charpy impact test specimens were prepared as per the ASTM standard for the measurement of mechanical properties.

\section{Mechanical tests}

Mechanical properties of the MWCNT/epoxy resin and GnP/epoxy resin composites were measured under tensile, compression, Izod and Charpy impact tests. The shape and size of the specimens were prepared according to the ASTM standard (Dassios et al. 2012). A dog bone-shaped tensile specimen size of $165 \times 5.3 \times 3 \mathrm{~mm}$ was used. The compression specimen size $(25 \times 7 \times 6.5 \mathrm{~mm})$ was used in short length to avoid the buckling effect. These tests were performed on the universal testing machine (UTM5T; SC Deys \& Company, Calcutta) with the cross-head speed of $0.05 \mathrm{~mm} / \mathrm{min}$. Load versus displacement results were used to measure elastic modulus under the tensile and compressive loading conditions. At least five specimens were tested for each sample with the variation of $10 \%$. The tensile strength, compressive strength and elastic modulus are reported on average. 
The impact test was performed with instrumented Izod and Charpy equipment (Model; Resil Impactor-50, CEAST, S. p. A., Italy). The impact hammer and vice lever with specimen adapter were used different in Izod and Charpy impact tests. The impact length and impact velocity were $0.327 \mathrm{~m}$ and $3.46 \mathrm{~m} / \mathrm{s}$. Izod and Charpy impact tests were performed on notched and un-notched sandwich specimens. The dimensions of Izod impact test were length $66 \mathrm{~mm}$, width $20 \mathrm{~mm}$, thickness $18 \mathrm{~mm}$. Charpy impact test dimensions are length $123 \mathrm{~mm}$, width $20 \mathrm{~mm}$ and thickness $18 \mathrm{~mm}$. A V-notch of depth $2 \mathrm{~mm}$ was introduced in Izod and Charpy impact test specimens.

Microstructure observation and surface analysis

The morphologies of the fractured specimens of graphene nanoplatelet/epoxy resin and MWCNT/epoxy resin composites were observed by scanning electron microscope (High resolution SEM SUPRA 40, 5 kV, Zeiss, Germany). TEM (Jeol JEM-2100, HR) was carried out to characterize the structure of nanotubes. To prepare TEM samples, some alcohol was dropped on the nanotubes film, then, these films were transferred with a pair of tweezers to a carboncoated copper grid.

\section{Results and discussion}

The SEM and TEM images of nanofiller are presented in Figs. 1, 2, 3. Figures 1, 2 clearly indicate that the nanofillers are well dispersed within the epoxy resin. It is obvious, from the images that all the nanofillers are hollow and tubular in shape as shown in Fig. 3a. In some of the images, catalyst particles can be seen inside the nanotubes. TEM images indicate that the nanotubes are high purity, with uniform diameter distribution and contain no

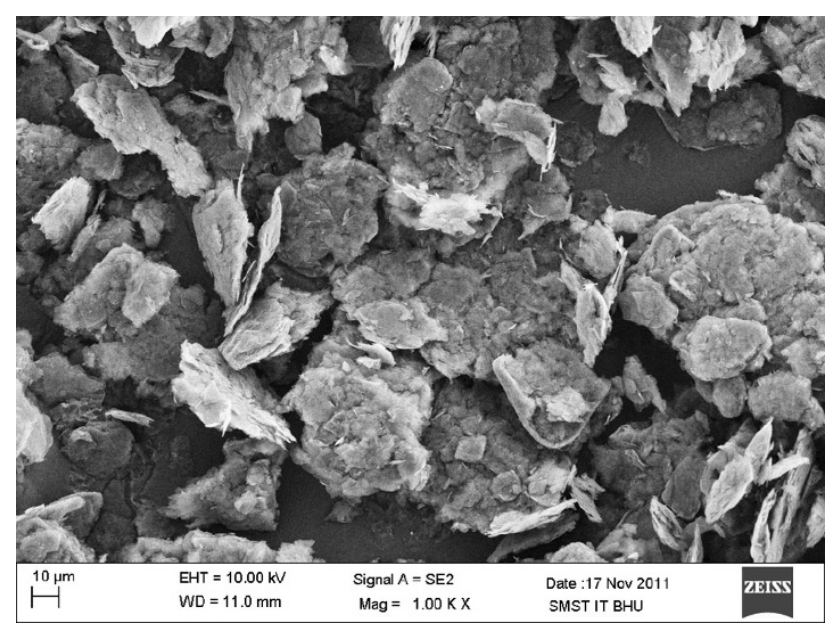

Fig. 1 SEM image of graphene nanoplatelet particles

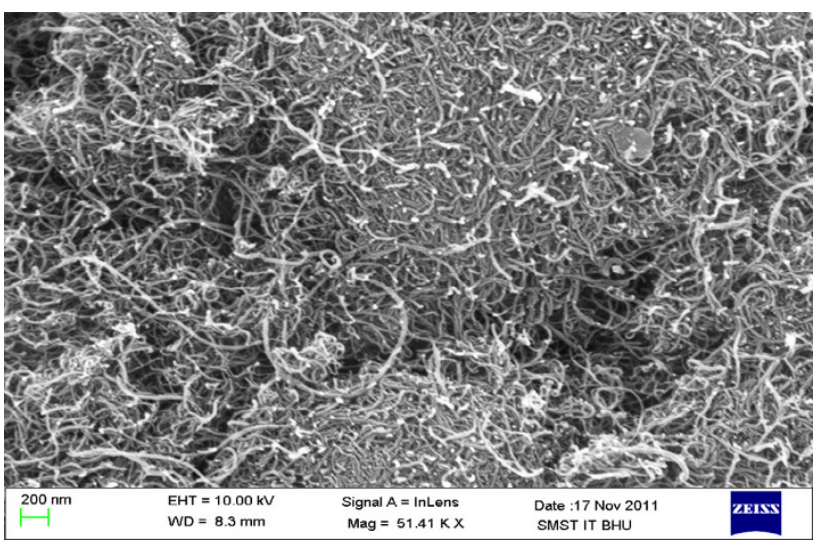

Fig. 2 SEM image of MWCNT particles

deformity in the structure. While Fig. $3 b$ shows the GnP particles interact well with each other at magnification of $20 \mathrm{~nm}$. This indicates that the GnP particles are dispersed uniformly within the epoxy resin.

To measure the influence of MWCNT and GnP nanofiller on mechanical properties of epoxy resin matrix, the samples with specific size of composite were prepared according to the requirements of tensile, compressive, Izod impact and Charpy impact tests. The tensile strength and compressive strength were obtained based on the maximum load. Figures 4, 5 show that the tensile strength and compressive strength increase with increase of weight percentage of nanofillers. The tensile strength and compressive strength of GnP/epoxy resin composite specimen give better strength compared to neat epoxy resin and MWCNT/epoxy resin composite specimens. However, the proper dispersion of nanofillers has great effect on the mechanical properties of the epoxy resin. The tensile strength and compressive strength of epoxy resin were increased about 20 and $31 \%$ with the addition of $\mathrm{GnP}$ filler, whereas tensile strength and compressive strength of epoxy resin were increased about 18 and $19 \%$ with the addition of MWCNT filler. These results clearly indicate that the nanofiller improve the tensile and compressive strength of epoxy resin. The results are parallel to other reported works (Dassios et al. 2012; King et al. 2013). It is now well known that the mechanical properties of nanofiller-filled polymer matrix, especially the strength and modulus depend to a great extent on filler dispersion and interfacial interaction. Modulus measurement by nanohardness followed the trends reported in the literature for polymers, that is, the modulus obtained was higher than the results obtained from macroscopic testing (King et al. 2013; Singh et al. 2013).

Izod impact and Charpy impact test results are shown in Figs. 6, 7. Also, dynamic fracture toughness $\left(\alpha_{k}\right)$ was calculated using the following equation (Gojny et al. 2005),

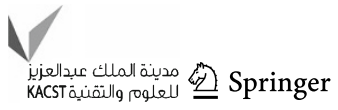




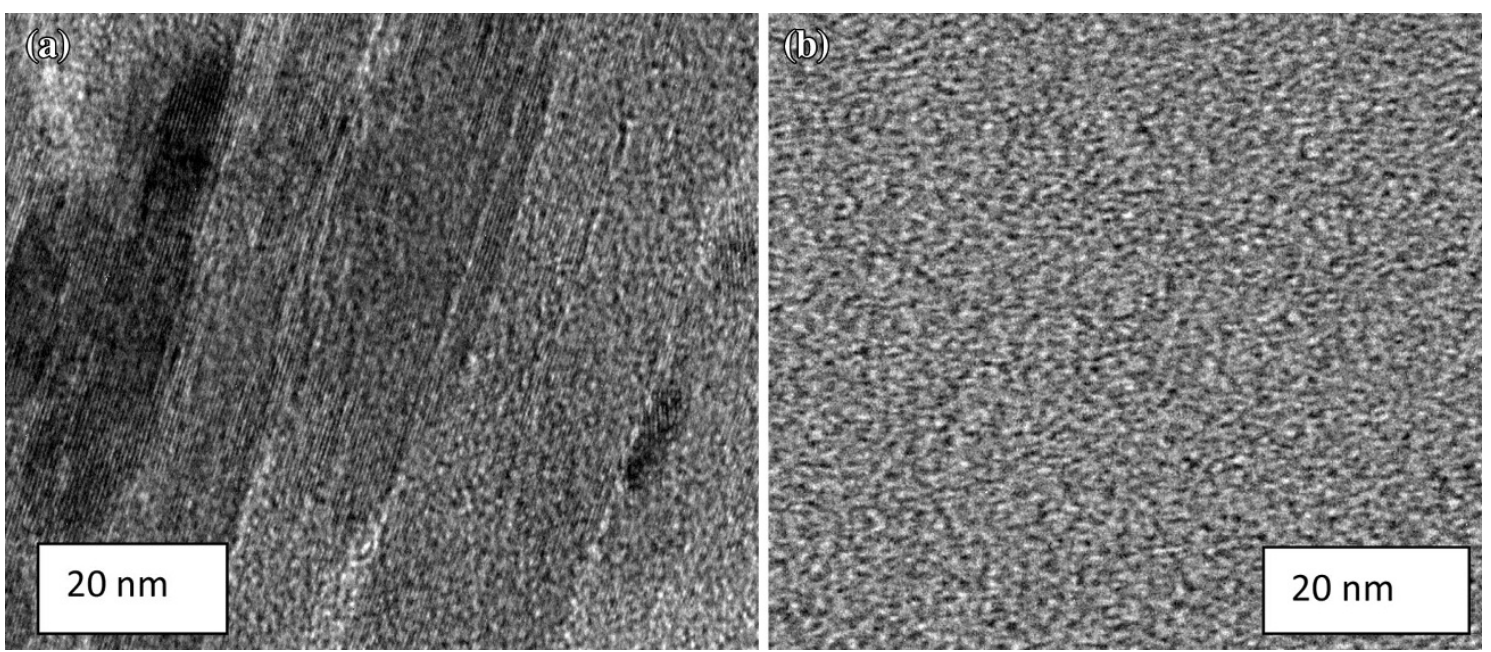

Fig. 3 TEM micrograph shows that interact with each other a MWCNT particles, b GnP particles

Fig. 4 Variation of tensile strength with weight percentage of nanofillers

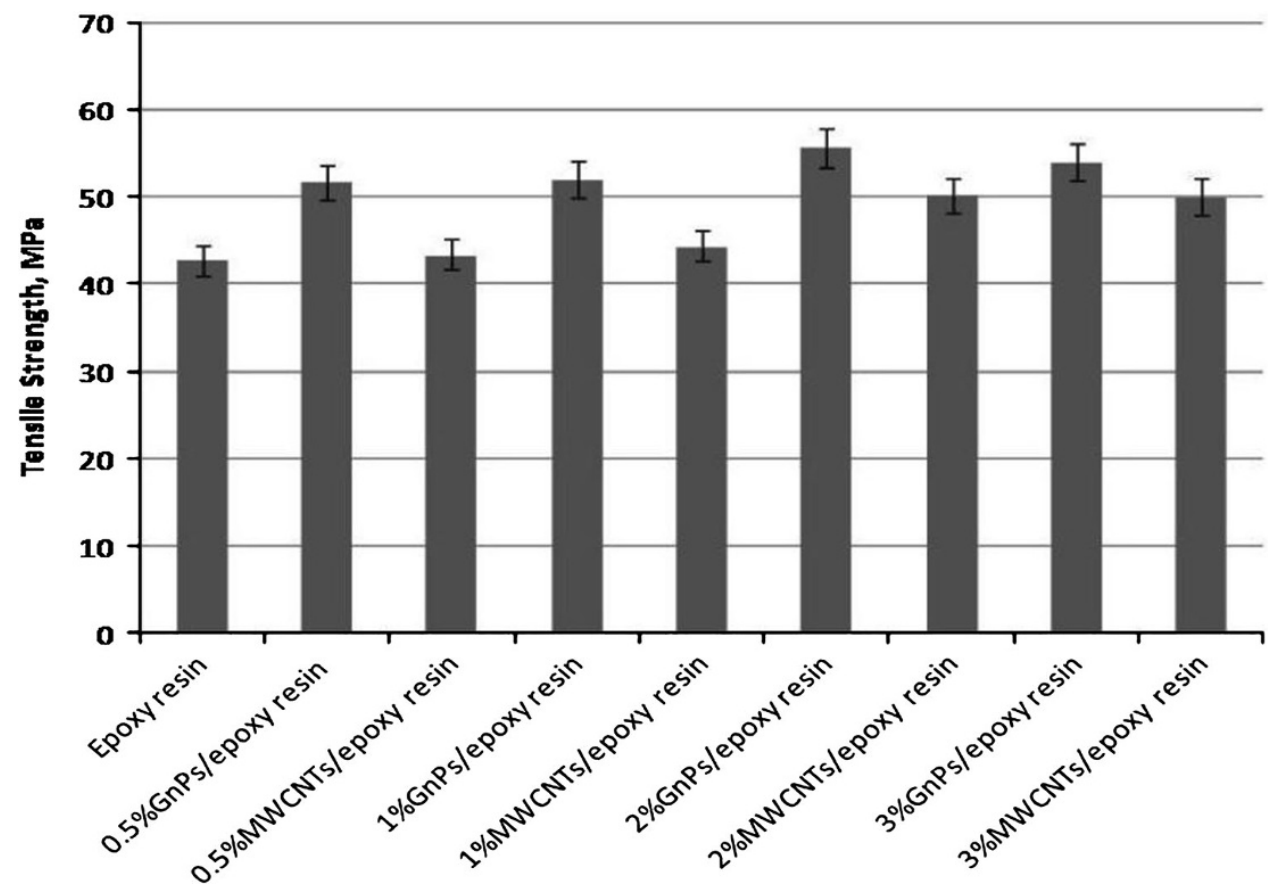

$\alpha_{\mathrm{k}}=\Delta E / w h$,

where $\Delta E$ is the absorbing energy of material during impact processing, $w$ and $h$ are the width and thickness of specimen, respectively.

The impact tests result shows that the MWCNT/epoxy resin composite gave higher Izod impact energy, Charpy impact energy, dynamic fracture toughness (Izod) and dynamic fracture toughness (Charpy) compared to $\mathrm{GnP} /$ epoxy resin composite and neat epoxy resin specimen as indicated in Figs. 6, 7, 8, 9.

Figures 6, 7 indicate the variation of Izod impact energy and Charpy impact energy with the percentage of filler ratio. The higher impact resistance clearly represents that the multi-walled nanotube absorbed more energy and it is dissipated within the area of nanotubes and take more time to penetrate the more area of the specimen (Singh et al. 2013). But, in the case of graphene nanoplatelets, impact energy spread easily all over the specimen because graphene nanoplatelets dispersed in the plate form. The reduced in absorbed energy may be caused by stress concentration in the vicinity of the graphene nanoplatelet (Chen et al. 2007); this typically occurs when hard fillers are incorporated into a brittle matrix. Besides, agglomeration of MWCNT/epoxy resin or GnP/epoxy resin 
Fig. 5 Variation of compressive strength with weight percentage of nanofillers
Fig. 6 Variation of Izod impact energy with weight percentage of nanofillers
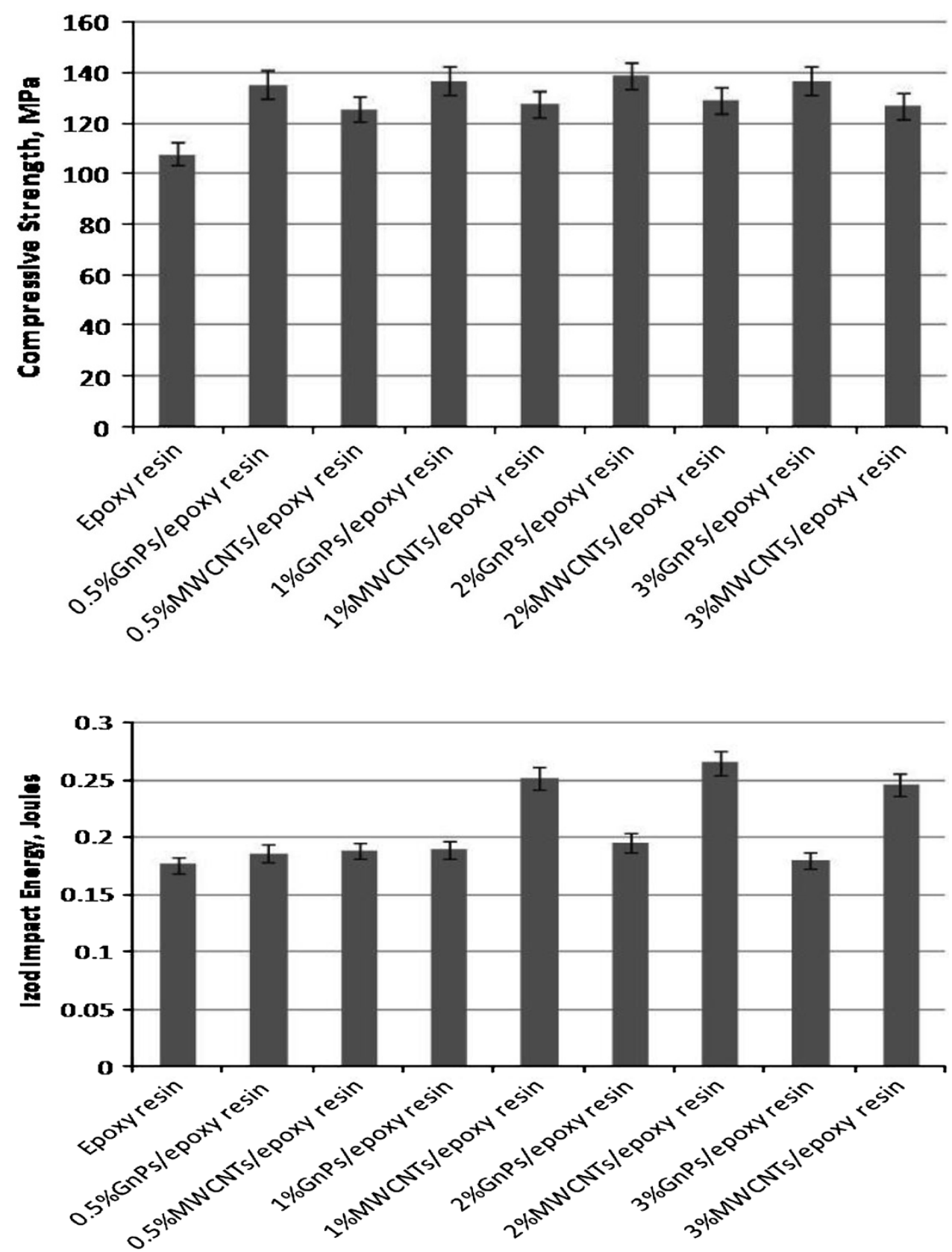

composites can lead to defects in the matrix that can act as seed points for crack initiation and premature fracture (Dassios et al. 2012; King et al. 2013).

Figures 8, 9 show the variation in dynamic fracture toughness under Izod and Charpy impact tests, which indicates the material toughness of neat epoxy resin, MWCNT/epoxy resin and GnP/epoxy resin composites. MWCNT/epoxy resin composite shows higher dynamic fracture toughness than the neat epoxy resin and $\mathrm{GnP} /$ epoxy resin composite. This result is evident that the lower weight fractions of nanofillers begin to agglomerate in epoxy resin. Figure 10 shows that MWCNT particle is well dispersed in epoxy resin, which indicates that the three mill rolling process is most suitable for dispersion of MWCNT in epoxy resin (Sinnott and Andrews 2001).

However, GnP nanofiller is not fully dispersed because of stirrer mixing process, as shown in Fig. 11. This highlights the need for continued research to develop new methods to enhance $\mathrm{GnP}$ dispersion at higher weight fraction (Han et al. 2007).

To understand the underlying mechanisms that are responsible for the improved performance of GnPs, we compared the thermal and microstructure chemistry of GnPs/epoxy resin and MWCNT/epoxy resin by TGA and 
Fig. 7 Variation of Charpy impact energy with weight percentage of nanofillers

Fig. 8 Variation of dynamic fracture toughness with weight percentage of nanofillers under Izod impact energy
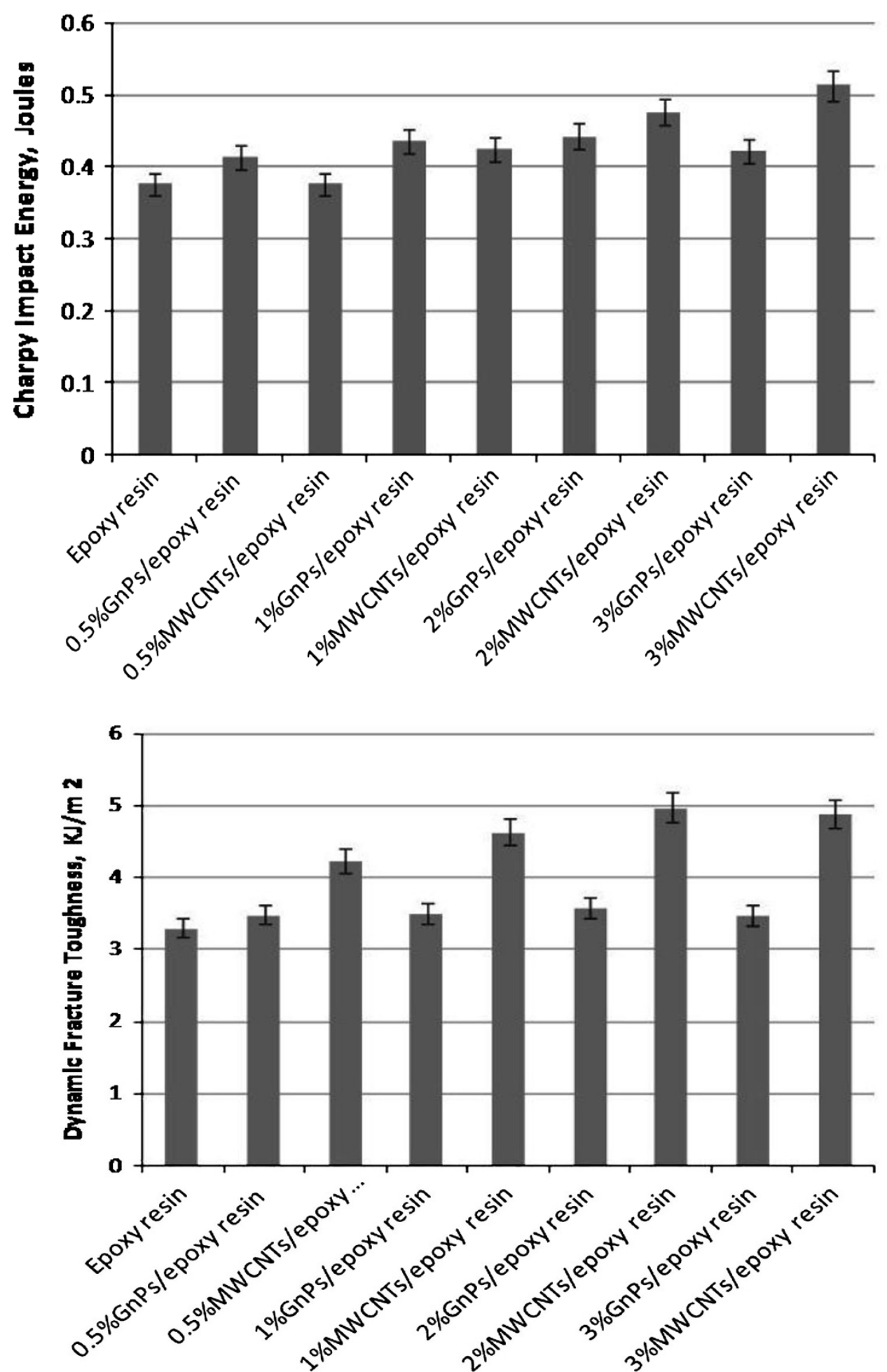

SEM analysis. We find that the MWCNT and GnP filler can be affected with the temperature due to variation in weight loss, as shown in Fig. 12. It is observed from the Fig. 12 that the nanocomposite made with MWCNT/epoxy resin can increase the initial decomposing temperature than the GnP-filled epoxy resin composite.
This means the percentage weight loss reduces abruptly with increase of temperature. MWCNT/epoxy resin composite could significantly enhance interfacial interaction between the MWCNT and epoxy resin matrix in composites (Singh et al. 2013). Where, GnP/epoxy resin composite reduces the stability of the composite at higher 
Fig. 9 Variation of dynamic fracture toughness with weight percentage of nanofillers under Charpy impact energy

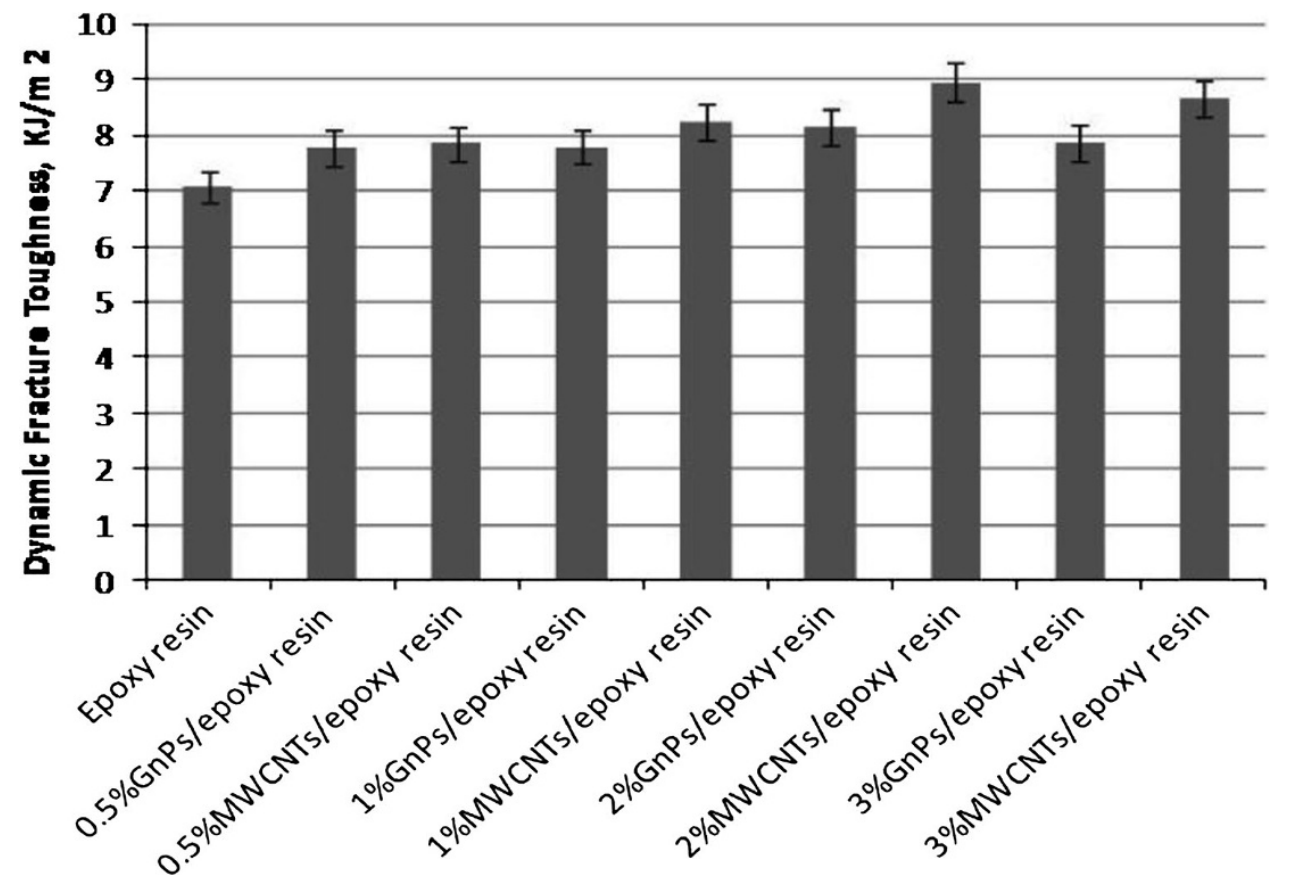

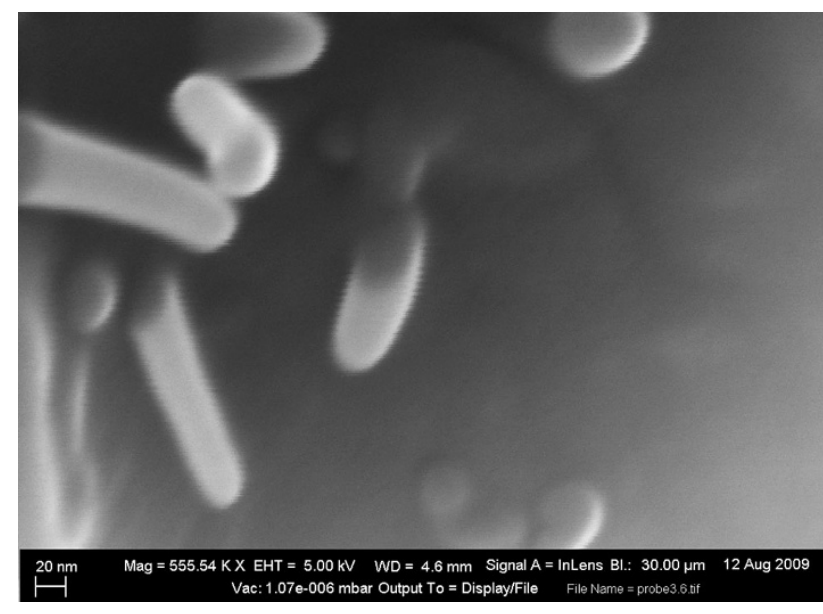

Fig. 10 SEM micrographs showing the dispersion of MWCNTs in epoxy resin

temperature, because $\mathrm{GnP}$ molecules can be retarded under high temperature. Therefore, dispersion of nanofillers can be improving the thermal stability of nanocomposites (Iijima 1991). But a noticeable increase in decomposition temperature was observed with incorporation of $2 \%$ MWCNT and GnP filler in epoxy resin. This was solely attributed to the synergistic effect of the composite structure formed between MWCNT and epoxy resin, as shown in Fig. 10. The increase through the synergistic effect was more than the composite containing GnPs $(0.5 \%)$, but considerably smaller compared to the composite containing $2 \%$ MWCNT. The likely possibility for this low increase compared to a binary system containing $2 \%$ MWCNT may be due to the effective low concentration of GnPs

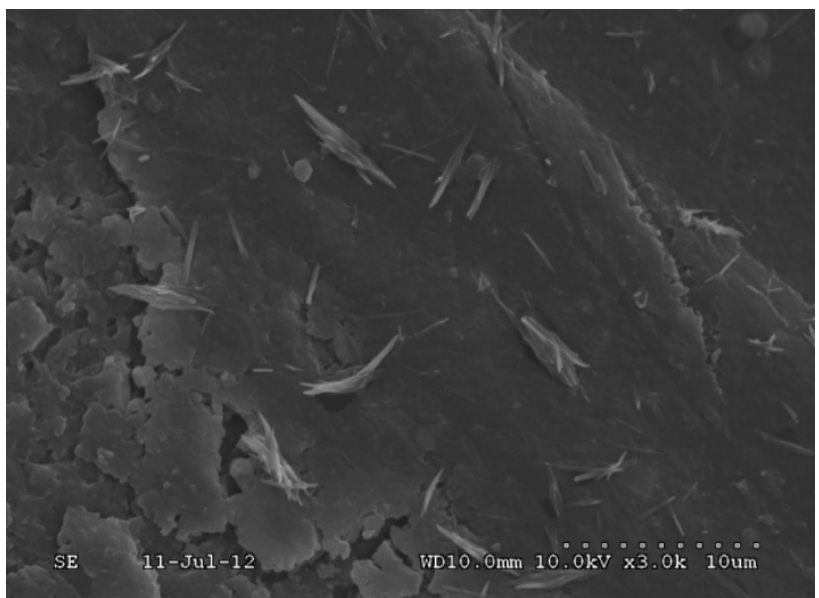

Fig. 11 SEM micrographs showing the dispersion of GnPs in epoxy resin

$(0.5 \%)$ in the epoxy resin. Another possible reason may be due to the fact that the high thermal conductivity of the MWCNT/epoxy resin composites resulted in a greater flow of heat throughout the sample. GnP/epoxy resin and MWCNT/epoxy resin composites started to lose weight as temperature increases continuously (Dassios et al. 2012) as indicated in Fig. 12.

Figure 13 shows SEM images of the fracture surfaces of GnP/epoxy resin composites. These composite fails in catastrophic mode. Figure 13a, b shows the fracture surface of the polymer composites made with GnPs, this clearly indicate that the epoxy resin fractured as a catastrophic pattern, because epoxy resin becomes more brittle due to addition of nanofillers. This shows the fracture surface of 


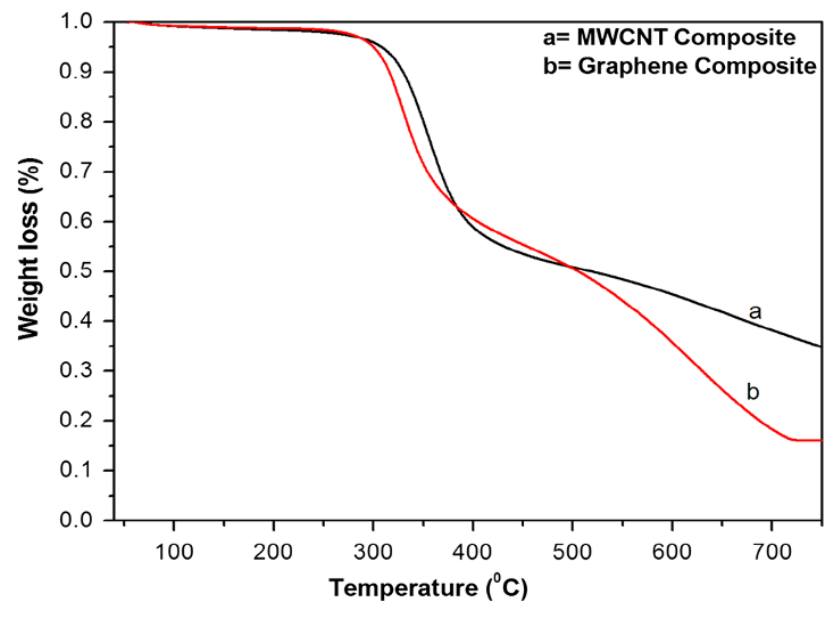

Fig. 12 Variation of weight loss with temperature composite made with graphene nanoplatelet. Micrographs indicate that the cracks were propagated at different planes and continued all around the specimen. Once cracks started, they spread quickly along the crack direction and then developed into macroscopic failure. Also, dispersion and agglomeration graphene nanoplatelet were clearly identified from the Fig. 13c, d. In most cases, the crack damage started from the interface, and then nanofillers suffered from the external force and were pulled out, leaving the smooth resin matrix which exposed the weak interfacial bonding. It was discovered that there were many CNT existing in the surrounding agglomerates, which might have been caused by the shear force around the nanofillers during the fabrication process, or by poor dispersion (Singh et al. 2013). However, the morphology of fractured sur-
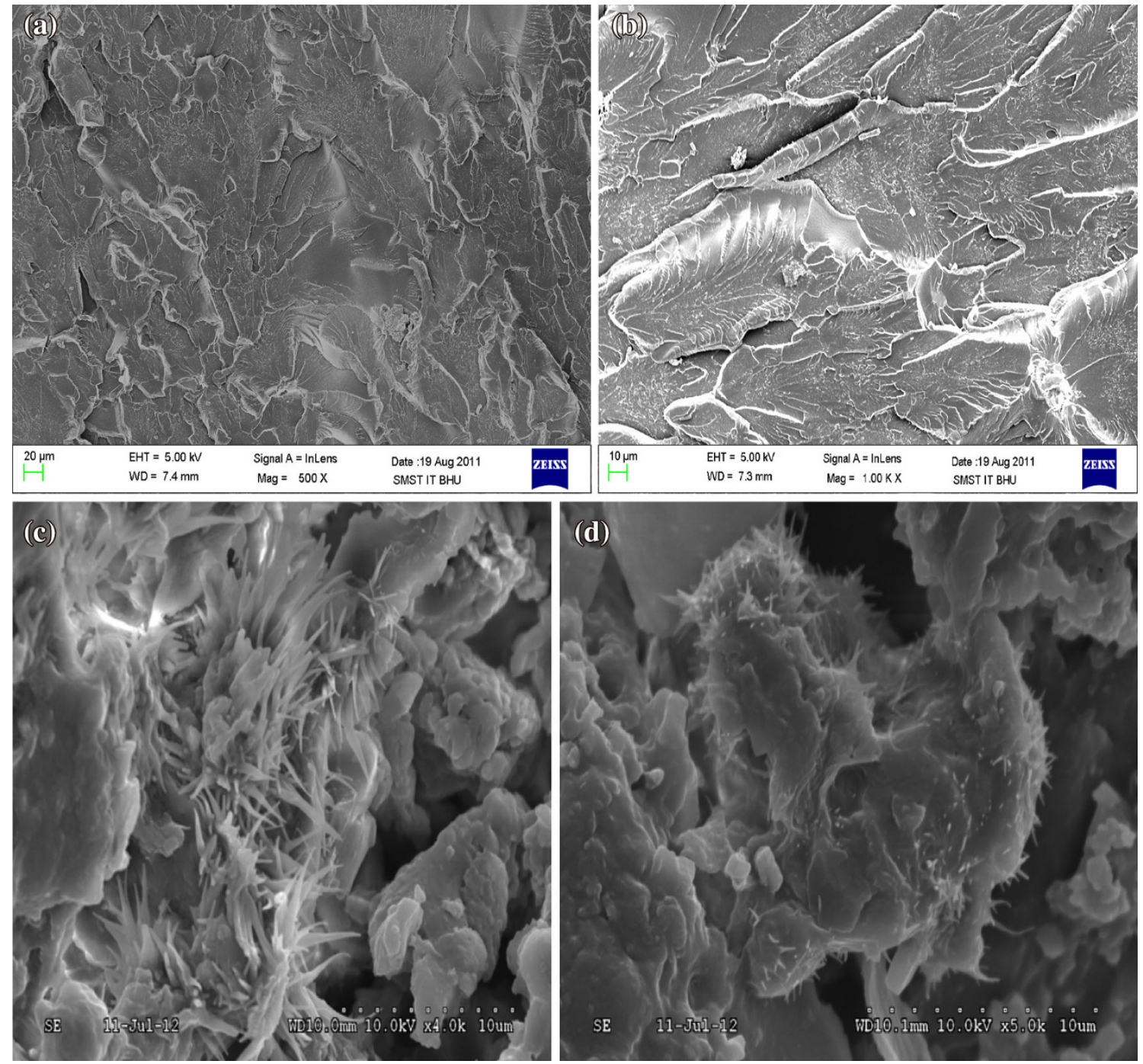

Fig. 13 SEM micrograph showing a microcracks formed in the resin area and $\mathbf{b}$ cracks formed around the graphene platelets, $\mathbf{c}$ graphene nanoplatelets agglomerated in the epoxy resin and $\mathbf{d}$ graphene nanoplatelets sticked with resin-like mushroom 
faces depicts the intimate contact and high embedding with polymer matrices, indicating good interfacial bonding between nanofillers and the epoxy resin. This further confirms that the presence of hydroxyl groups on graphene nanoplatelet surfaces has a strong interaction with the epoxy resin and significantly improves adhesion at interfaces. In general, nanoplatelets can be easily attracted to each other due to their very high specific area and high surface energy, due to these properties, tensile and compressive strength of $\mathrm{GnP} / \mathrm{epoxy}$ resin composite give more value compared to MWCNT/epoxy resin composite (King et al. 2013).

\section{Conclusion}

Based on the experimental observation, the results clearly indicate that the GnP and MWCNT nanofiller can improve the performance of epoxy resin. The tensile strength and compressive strength of $\mathrm{GnP} / \mathrm{epoxy}$ resin composite are higher than those of the MWCNT/epoxy resin composite with the variation of weight percentage of nanofiller ranging from $0.5,1,2$ and 3 . Whereas, MWCNT/epoxy resin composite gives higher impact resistance compared to $\mathrm{GnP} /$ epoxy resin composite at the same variation of nanofiller. The results of this study suggest that MWCNT plays an important role of absorbing the impact resistance because nanotube dampens the more energy compared to graphene nanoplatelet. On the other side, tensile strength and compressive strength of GnPs/epoxy resin increase due to more surface area and significant increase in the interfacial contact area of graphene nanoplatelet compared to multi-walled carbon nanotube. The GnPs are more effective than MWCNT, which contributes to better interfacial binding. These results indicate that GnPs show significant potential as a structural reinforcement additive in polymerbased composite materials.

Acknowledgments The authors are thankful to School of Materials Science and Technology, Department of Mechanical Engineering, Indian Institute of Technology, (BHU), Varanasi, India and Department of Science and Technology, New Delhi, India for their supports.
Open Access This article is distributed under the terms of the Creative Commons Attribution License which permits any use, distribution, and reproduction in any medium, provided the original author(s) and the source are credited.

\section{References}

Chen Z, Lin YM, Rooks MJ, Avouris P (2007) Graphene nanoribbons electronics. Phys E 40:228-232

Dassios KG, Musso S, Galiotis C (2012) Compressive behaviour of MWCNT/epoxy composite mats. Compos Sci Technol 72:1027-1033

Gojny FH, Wichmann MHG, Fiedler B, Schulte K (2005) Influence of different carbon nanotubes on the mechanical properties of epoxy matrix composites-a comparative study. Compos Sci Technol 65(15-16):2300-2313

Han MY, Oezyilmaz B, Zhang Y, Kim P (2007) Energy band-gap engineering of graphene nanoribbons. Phys Rev Lett 98:206805

Higginbotham AL, Kosynkin DV, Sinitskii A, Sun Z, Tour JM (2010) Low defect graphene oxide nanoribbons from multiwalled carbon nanotubes. ACS Nano 4:2059-2069

Iijima S (1991) Helical microtubules of graphitic carbon. Nature 354:56-58

Jiao L, Zhang L, Wang X, Diankov G, Dai H (2009) Graphene nanoribbons from carbon nanotubes. Nature 458:877-880

King JA, Klimek DR, Miskioglu I, Odegard GM (2013) Mechanical properties of graphene nanoplatelets/epoxy composites. J Appl Polym Sci 128:4217-4223

Kosynkin DV, Higginbotham AL, Sinitskii A, Lomeda JR, Dimiev A, Price BK, Tour JM (2009) Longitudinal unzipping of carbon nanotubes from graphene nanotubes. Nature 458:872-876

Li X, Wang X, Zhang L, Lee S, Dai H (2008) Chemically derived ultrasmooth graphene nanoribbon semiconductors. Science 319:1229-1232

Rafiee MA, Lu W, Thomas AV, Zandiatashbar A, Rafiee J, Tour JM, Koratkar NK (2010) Graphene nanoribbon composites. ACS Nano 4(12):7415-7420

Singh S, Srivastava VK, Prakash R (2013) Characterization of multiwalled carbon nanotube reinforced epoxy resin composites. Mater Sci Technol 29(9):1130-1134

Sinnott SB, Andrews R (2001) Carbon nanotubes: synthesis, properties, and applications. Crit Rev Solid State Mater Sci 26:145-249

Stankovich S, Dikin DA, Dommett GHB, Kohlhaas KM, Zinney EJ, Stach EA, Piner RD, Nguyen ST, Ruoff RS (2006) Graphenebased composite materials. Nature 442:282-286

Wang X, Li X, Zhang L, Yoon Y, Weber PK, Wang H, Guo J, Dai H (2009) N-dopping of graphene through electrothermal reactions with ammonia. Science 324:768-771 